\title{
The locus of written corrective feedback in various SLA theories
}

\author{
Ehsan Abbaspour \\ Abbaspour1986@gmail.com \\ Science and Research Branch, Islamic Azad University, Tehran, Iran
}

\begin{abstract}
Whether corrective feedback is effective in L2 writing has always been a controversial issue among Second Language Acquisition (SLA) scholars despite a vast body of research investigating the issue. This conflict is rooted in the fact that different researchers subscribe to different theories of SLA which are at times contradictory in nature. The present article reviews and investigates major SLA theories with respect to their views and stance toward the efficacy of Written Corrective Feedback (WCF) and error correction in second language writing. Many of these theories do not address the role of corrective feedback explicitly or merely focus on the role of oral feedback. Polio (2012) and Bitchener and Ferris (2012) have partially investigated the issue at stake reviewing a number of SLA theories. In this study, however, attempt is made to shed light on the role of WCF especially in the theories which are not directly concerned with L2 writing.
\end{abstract}

Keywords: Second language acquisition, second language writing, written corrective feedback 


\section{Introduction}

To date, numerous studies have investigated the efficacy of Written Corrective Feedback (WCF) in Second Language Acquisition (SLA). However, the findings are still far from consensus and in many instances discrepant. The controversy over the efficacy or the inefficacy of WCF reached its climax with the publication of Truscott's (1996) seminal article where he claimed that "grammar correction has no place in writing courses and should be abandoned" (p. 328). To make his point, Truscott mentioned a number of experimental studies which had proved WCF ineffective. This radical view propelled a massive wave of research studies aiming at proving Truscott wrong (e.g., Ferris, 1999; Chandler, 2003). One of the counterarguments was that Truscott had cherry-picked the studies the underlying assumptions of which are in line with the UG-based SLA theory to which Truscott subscribes. This controversy is the main impetus for the current study.

This study aimed at reviewing and investigating various SLA theories with respect to their views toward the role of WCF. Many of these theories only minimally address the role of feedback in general and WCF in particular are mainly neglected. This oversight is basically a result of the view that language is primarily speech. Polio (2012), as well as Bitchener and Ferris (2012), has investigated the role of WCF in some of the most well-known SLA theories. Regarding the theories which have not addressed the role of WCF explicitly, they resorted to deduction and inference. The present article, however, is informed by constructive discussions with many prominent figures in various SLA theories to elucidate the ambiguous matters.

The study reviews seven categories of SLA theories namely, UG-based theories (Monitor Model), Modular theories (Autonomous Induction Theory), Emergentist theories (Associative Cognitive CREED and Competition Model), Information Processing theories (ACT Model and Skill Acquisition Theory), Input Processing theories (Processing Instruction Theory and Processability Theory), Interactionist theories (Interaction Hypothesis and Comprehensible Output Hypothesis), and Sociocultural Theory (including Activity Theory). This article by no means intends nor is in its scope to thoroughly evaluate or critique the SLA theories. It also must be mentioned that in this article, terms 'model', 'hypothesis', 'framework', and 'theory' are used interchangeably adopting the original terminology used by the proponents of each theory. 


\section{UG-based Theories}

\subsection{Monitor Model}

Probably, the most typical instantiation of the Universal Grammar (UG) in SLA is the Monitor Model proposed by Krashen (1977) where he delineated his controversial idea that instruction is ineffective in L2 acquisition. Krashen's $(1977$; 1981; 1982; 2003) formulated model is composed of five hypotheses:

1. Acquisition-Learning Hypothesis: Drawing on the Chomskyan Competence/Performance dichotomy, Krashen makes a distinction between 'acquisition' and 'learning'. In this hypothesis, acquisition is defined as the natural and subconscious process in which acquirers obtain L2 competence similar to children's implicit internalization of their L1. On the other hand, learning refers to "conscious knowledge of a second language, knowing the rules, being aware of them, and being able to talk about them" (Krashen, 1982, p. 10). The distinction is similar to the implicit/explicit learning dichotomy.

2. Natural Order Hypothesis: Based on the findings of morpheme studies (Dulay \& Burt, 1974), this hypothesis claims that certain morphemes are learned before others in a predictable order which cannot be skipped through instruction.

3. Monitor Hypothesis: In the same vein as Acquisition-Learning Hypothesis, Monitor Hypothesis posits that the learned system is not able to produce spontaneous speech and only acts as a monitor checking the spontaneously produced speech by the acquired system. In other words, the learned knowledge is no more than a metalinguistic knowledge which has nothing to do with language production except for auditing the accuracy of the output.

4. Input Hypothesis: Krashen (1982) believes that this hypothesis is the most important one as it answers the crucial question of 'How is a language acquired?'. He explains that if ' $i$ ' is the acquirers' current competence, the acquirer can only understand a little beyond their current competence which he refers to as ' $i+1$ '. We understand (and eventually acquire) this ' +1 ' information by using the "context, our knowledge of the world, our extralinguistic information to help us understand language directed at us" (Krashen, 1982, p. 21). This hypothesis also claims that we first acquire the meaning then we acquire the language structures (forms). As a result, according to this hypothesis, spoken fluency cannot be taught explicitly, rather it gradually emerges. In sum, this hypothesis assimilates 
SLA to children's L1 acquisition process where caretakers rough-tune their speech while talking to children (i+1).

5. Affective Filter Hypothesis: This hypothesis focuses on the affective factors impacting SLA (i.e., motivation, attitude, anxiety, etc.). Krashen (1982) pinpoints that those with higher affective filters (e.g., low attitude or high anxiety) are less likely to acquire the language optimally as they seek less input and the input will not reach the language acquisition device responsible for processing the input.

\subsection{The Role of WCF in Monitor Model}

The Monitor Model takes the most conspicuous stance toward the efficacy of corrective feedback in L2 acquisition. As mentioned above, according to this model, explicit instruction (including corrective feedback) only leads to learning which functions merely as a monitor and the acquisition process is essentially implicit. With respect to WCF, Krashen (1984, p. 44) asserts that "[e]rror correction, according to the theory, affects only conscious learning, not acquisition. Error correction helps the learner adjust his conscious mental representation of the rule. As in the case of writing, research has failed to confirm that error correction has a significant impact on second language acquisition".

\section{Modular Theories}

Modular theories in SLA draw on Fodor's (1983) Modularity of Mind which proposes that there is a linguistic core/module responsible for linguistic knowledge which is distinct from other knowledge cores/modules.

In this section, Autonomous Induction Theory (AIT) is discussed which relies on Jackendoff's $(1997,2002)$ theory of linguistic modularity called Representational Modularity. This version of modularity claims that the formal linguistic aspects of phonology and syntax are processed in linguistic-specific sub-modules and we cannot control these processes. However, "[t]he outputs of these sub-modules come together at interfaces, including an interface with real world knowledge - that is available to conscious processing" (Whong, 2007, p. 146). Jackendoff's modularity is different from Fodor's in that for Fodor language module is unique and domainspecific but Jackendoff maintains that during L2 acquisition, different modules (e.g., hearing, vision, etc.) are in interaction. 


\subsection{Autonomous Induction Theory (AIT)}

Central to the AIT is the role of input which is defined quite differently in this theory. That is why Carroll (2001) believes that none of these approaches has satisfactorily addressed the issue of input and claims that there is no theory for input in SLA. As noted by Sharwood Smith (2013), it was Carroll who first emphasized the importance of a decent definition of input. According to Carroll (1999), the language to which the learners are exposed is not to be considered as input, rather as stimuli. These stimuli provide the raw material (unanalyzed data) on which learners' perceptual and representational capacities work. Carroll $(2001,2002)$ distinguishes the input to speech processing from the input to learning mechanisms. Both of these inputs are inaccessible to conscious noticing meaning that L2 learners cannot consciously notice in the language spoken to them what they know or what they do not know.

Besides Representational Modularity, Induction Theory is another crucial component of the AIT. Carroll (1999, p. 375) claims that "[i]nduction can recombine features in limited ways (consistent with the formal and functional universals of UG) to create new categories, and reorganize the positions of units within linguistic structures". Carroll (2001, p. 120) draws a distinction between inductive reasoning and inductive learning (I-learning) by stating that inductive reasoning is "associated with problem-solving, hypothesis-formation and hypothesistesting" and is not directly involved in how a learner acquires a set of rules. I-learning, on the other hand, is defined by Carroll (2002) as:

a process that leads to the revision of perceptual and parsing procedures so that they can analyze novel stimuli made available to the organism through the perceptual systems. Ilearning is not inductive reasoning. It is also different from mechanistic responses to environmental change in that the results of i-learning depend upon the contents of symbolic representations in working memory and long-term memory. (p. 229)

In this framework, language is processed in a faculty of mind with a characteristic chain of levels of representation. Thus, for language acquisition there is a phonology, a morphosyntax, and a conceptual structure level, all linked directly via correspondence rules. Each of these levels is autonomous. Two types of processors are at work for each level of representation: the integrative processor which maps smaller representations into larger units and the correspondence processor which is responsible for moving the representations from one level to the next (e.g., from phonological level to morphosyntactic level). Together, the two processors form an encapsulated 
and sequential module (Sun, 2008). What is important is that each processor should receive its proper input, otherwise it fails to analyze.

\subsection{The Role of WCF in AIT}

In the AIT, feedback and correction play a part in the creation of novel forms of grammatical knowledge. Moreover, they are assumed to be input for learning mechanisms. L2 learners must be equipped with the required metalinguistic capacity to be able to interpret the feedback they receive. Thus, corrective feedback cannot be interpretable by young learners (below the age of 5) due to the lack of such a capacity. Accordingly, Carroll (2001) asserts that "[a]dult learners can learn abstract linguistic generalizations on the basis of various types of explicit and implicit feedback and are not restricted to instance-based learning or modeling” (p. 341) although only particular types of feedback help learners to generalize.

For corrective feedback to be effective, Carroll (2001) places certain restrictions. Firstly, feedback does not enable the learners to learn the basic features of the grammar; therefore, they cannot learn the morphosyntactic features which are absent in their L1. Secondly, if the conceptual units do not closely correspond with the grammatical categories, the learners cannot learn from the feedback. Finally, for more advanced learners, feedback is redundant because the feedback provider (i.e., the teacher) cannot easily discern error from random slips (i.e., mistakes).

With respect to the aforementioned restrictions, Carroll believes that corrective feedback cannot play a crucial role in SLA. However, Carroll (personal communication, April 19, 2019) expresses more reservations regarding the efficacy or inefficacy of corrective feedback in written language and she calls for further studies on the issue. This uncertainty is rooted in the fact that written language is fundamentally different from spoken language. As she further explains, there are three kinds of structure for spoken language (i.e., prosodic, morphosyntactic, and conceptual), whereas there are four kinds of structure for written language (i.e., prosodic, morphosyntactic, conceptual, and graphic). They must all be connected by associative learning mechanisms as well as a priori constraints on those associations. In other words, there are biases to map a certain kind of structure onto other kinds of structures (or in Jackendoff's (1997) words "correspondence rules"). In sum, it can be concluded that, due to the different and complex nature of written language, AIT does not have a clear answer to the question of where WCF leads to better learning (sustainable internalization) of the language. 


\section{Information Processing Theories}

\subsection{ACT (Adaptive Control of Thought) Model}

The ACT model was developed by Anderson (1983) who advocates that human cognition is unitary. In other words, all the higher cognitive processes (i.e., memory, problem-solving, deduction, imagery, induction, and language) are different representations of the same basic system. ACT is a kind of cognitive architecture defined by Byrne (2002) as "a broad theory of human cognition based on a wide selection of human experimental data and implemented as a running computer simulation program" (p. 2).

The underlying assumption in all different versions of ACT Model (i.e., ACTE, ACT*, and ACT-R) "is that human cognition emerges through an interaction between a procedural memory and a declarative memory" (Anderson \& Gluck, 2001, p. 228). Declarative memory consists of facts (such as $2+3=5$ ), and procedural memory consists of our knowledge of how to do things.

Another common characteristic between these all is that learning occurs in three stages: a declarative stage, a compilation stage, and a tuning stage (Anderson, 1982, 1983). In Stage 1, declarative knowledge is stored as facts in units called chunks. During the second phase, these declarative facts are converted into procedural knowledge through knowledge compilation. Procedural knowledge is also stored in units called productions (if-then pairs). As R. Ellis (2008, p. 428) explicates, there are two mechanisms at work during the process of knowledge compilation, composition which denotes "collapsing several discrete productions into one", and proceduralization which refers to "applying a general rule to a particular instance".

For example, if the learner considers adding -ed to the end of the verb for generating past tense a general rule, this may lead to the incorrect from * goed instead of 'went'. Anderson (1983) notes that errors usually emerge during this stage. In the final phase, in which procedures become more automated, the mind manages both to generalize productions and also to discriminate irregular structures. For example, "the learner may modify the past tense production and apply to only a subset of verbs. At this stage, the ability to verbalize knowledge of the skill can disappear entirely" (Ellis, 2008, p. 428).

Moreover, all the members of the ACT family are influenced by the notion of the Fan effect, which according to Anderson and Reder (1999) refers to "the phenomenon that, as participants study more fact about a particular concept, their time to retrieve a particular fact about 
that concept increases." (p. 186). This phenomenon, as Anderson, Fincham, and Douglass (1999) argue, puts an emphasis on the role of practice in skill acquisition.

In the same vein, with respect to the declarative vs. procedural knowledge dichotomy, Paradis (2009) maintains that we use our declarative memory to learn declarative knowledge (which is explicit) and our procedural memory system to learn procedural knowledge (which is implicit). There is no communication whatsoever between these two memory systems. Paradis also explicates that children acquire language implicitly (as an automated/proceduralized skill) while adults employ their declarative memory system to learn a language. More directly related to the role of corrective feedback, he claims that explicit knowledge cannot be transformed into implicit knowledge as each develops and operates independently of the other.

\subsection{Skill Acquisition Theory}

Skill acquisition theories originate in cognitive psychology; so they view language learning as similar to learning other skills. McLaughlin (1987) states that "to learn a second language is to learn a skill, because various aspects of the task must be practiced and integrated into fluent performance" (p. 133). In this view, SLA is considered to be a complex task with a hierarchical structure similar to other tasks which include sub-tasks. Lower-level tasks are automatized via practice and stored in long-term memory.

McLaughlin (1987) states that there are two information processing modes in play during the process of language acquisition, automatic and controlled. Automatic processing involves "the activation of certain nodes in memory every time the appropriate inputs are present. This activation is a learned response, which has been built up through the consistent mapping of the same input to the same pattern of activation over many trials" (p. 134). Controlled processing, unlike automatic processing, is not a learned response and is under attentional control. Through controlled processing, the flow of information is regulated from short-term to long-term memory.

McLaughlin, however, believes that the concept of automatization alone does not shed light on the whole picture of language learning. Whereas, language learners need to organize the acquired information which takes place through restructuring.

Drawing on Karmiloff-Smith (1986), McLaughlin (1987) argues that restructuring entails three phases, the data-driven phase, where the learner masters the components of the task, the organization phase, where the learner "attempts to simplify, unify, and gain control over the 
internal representation" (p. 137), and the integration phase where the two previous phased are integrated and a unified representational framework is formed.

\subsection{The Role of WCF in Information Processing Theories}

Drawing on the Skill Acquisition theory, Johnson $(1988,1996)$ pinpoints the significance of corrective feedback (or what he calls "mistake correction") by saying that the instructional sequence must be like learn $\rightarrow$ perform $\rightarrow$ learn rather than the traditional learn $\rightarrow$ perform one. He asserts that after the 'perform' stage, there must be an opportunity for extrinsic feedback provided by the teacher as the learners cannot be expected to be able to detect their errors automatically. Johnson (1988, p. 93) believes that the learners "need to see for themselves what has gone wrong, in the operating conditions under which they went wrong". He further states that explanation is not the best choice for error correction and reformulation (modeling the correct language form) will serve the purpose of the conversion of declarative knowledge to automatized/procedural knowledge better.

Along the same line, Paradis (2009) claims that implicit knowledge is more fundamental because it is what is used from an earlier age and gives automatic access to language. It is, therefore, faster and more systematic. But when the language is appropriated in adulthood, some feedback is necessary to be able to practice (and, hopefully, eventually acquire the nonsalient forms).

As of yet, not many empirical studies have investigated the efficacy of WCF through the lens of this theory. However, in a study conducted by Hartshorn, Evans, Merrill, Sudweeks, Strong-Krause, and Anderson (2010) as well as in its replication by Evans, Hartshorn, and StrongKrause (2011), the researcher utilized an instructional methodology they called "dynamic WCF". According to Hartshorn et al. (2010), “ “.. proceduralization requires extensive and deliberate practice, which then leads the learner toward greater automatization' (p. 87). Therefore, they proposed that written feedback, in order to be effective needs to be meaningful, timely, constant, and manageable. The feedback cycle the researchers used is illustrated in Figure 1. 


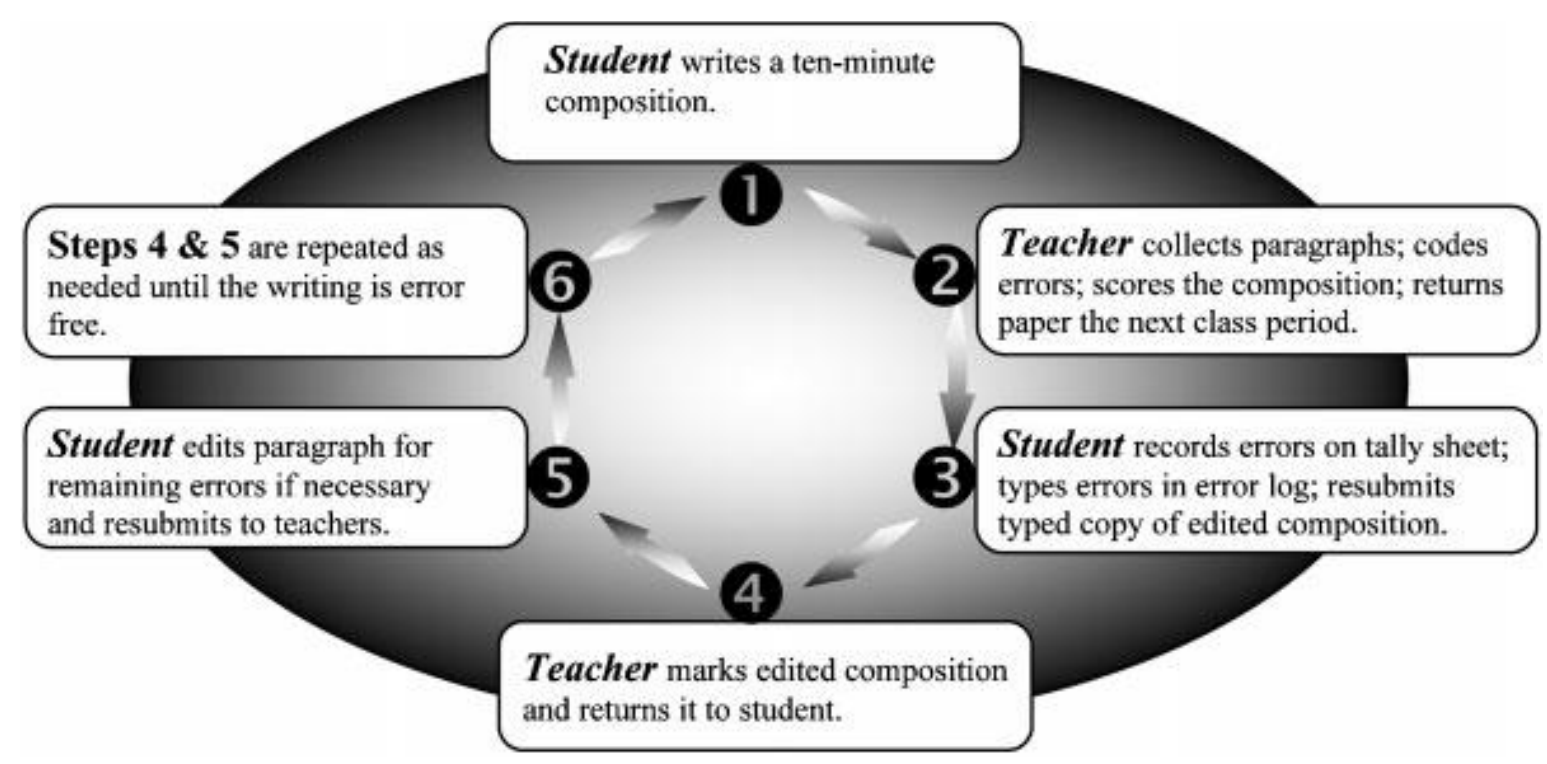

Figure 1: Feedback cycle for dynamic written corrective feedback (Hartshorn et al., 2010 p. 90)

The researchers concluded that the treatment had a relatively large effect on improving the mean accuracy scores of those students in the treatment group compared with those in the contrast group (where the students received traditional direct WCF). Although there were no statistical differences between the two groups over time, in terms of their mean rhetorical competence ratings, writing fluency scores, or writing complexity scores, the traditional approach to process writing slightly favored the contrast group in terms of writing fluency and writing complexity.

\section{Input Processing Theories}

\subsection{Processing Instruction Theory}

VanPatten and Cardieno (1993) propose three distinguishable types of processing in acquisition, the processes that convert the input to intake which they called input processing, those that promote the inclination of intake and restructuring of the internalized linguistic system, and the ones that set out to gauge the amount of learned language based on production (monitoring, accessing and control). However, input processing actively is in response to the processes that are intake providers; simply strategies and mechanisms that increase form-meaning connection.

In this model, the significant place of input in language learning is prominently concerned as VanPatten (2009) accords two major phenomena that happen simultaneously with L2 utterances. Firstly, an attempt to understand what was said is made, secondly, meaning is mapped 
onto form using the internal processer. These can be induced as the building blocks of the Information Processing model.

Input Processing is defined as "the initial process by which learners connect grammatical forms with their meanings as well as how they interpret the roles of nouns in relationship to verbs" (VanPatten, 2004, p. 5). Thus, VanPatten (2002; 2004; 2009) is basically concerned with the connection between form and meaning in the input and linking them to acquisition. Input processing is a branched model of information processing which strives to distinguish between the main potential role of input processing in comprehension rather than production; in other words, input processing is not a model of acquisition. In fact, mechanisms through which learners restructure grammar (the ability to use language in communication and factors related to the acquisition of fluency in output) is not in the scope of input processing (VanPatten, 2004).

One of the manifestations of input processing in language learning pedagogy is Processing Instruction (PI) which carries three major components. Firstly, learners are explicitly informed about how a particular linguistic structure works. Also, the learners are informed about the strategies that can aid the learners with the proper form-meaning connection. Finally, the learners are given structured input (SI) activities which are structurally manipulated so that they push learners away from non-optimal form-meaning connecting activities (Wong, 2004).

Wong (2004) introduced two types of PI activities as referential and affective. Referential activities require learners to focus on form for meaning and have a right or wrong answer to scrutinize the proper form-meaning connection. Affective activities do not have a right or wrong answer whereas they push learners to engage in information processing expressing an opinion and/or belief.

\subsection{The Role of WCF in Processing Instruction Theory}

In this theory, structured input is considered superior to explicit instruction since it is believed that explicit knowledge cannot become implicit. Generally speaking, PI sees the provision of corrective feedback as unnecessary since the theory basically focuses on internal processing on the part of the learners rather than teacher intervention in the form of corrective feedback. Also, as VanPatten (personal communication, March 31, 2018) states, "during PI, learners do not create output so there is no reason to provide feedback in the traditional sense". This clearly implies that explicit 
correction has no place in spoken or written language. However, no study has investigated WCF within this theory.

The inefficacy of explicit instruction in general and corrective feedback in specific from the perspective of PI is also evident in VanPatten \& Oikkenon (1996), Benati (2004,) Sanz \& Morgan-Short (2004), and Henry, Culman \& VanPatten (2009).

\subsection{Processability Theory}

Processability Theory was generated in SLA from the application of the Multidimensional Model (Meisel, Clahsen, \& Pienemann, 1981). Pienemann's (1984; 1989; 1998; 2005) Processability Theory is based on Krashen's Natural Order Hypothesis, and the idea of the efficiency of explicit instruction. Accordingly, Pienemann believes that the acquisition of target language morphosyntactic structures is restricted by predictable and sequential stages. This means that language learners gradually will be capable of sharing information across the elements of a sentence (Mitchell, Myles \& Marsden, 2013). The first stage in this hierarchy is characterized by the complete absence of any language-specific procedures. New words have to be entered into the lexicon. Once L2 lexical items have been assigned a grammatical category, lexical morphological markers can be produced. Upon the development of the phrasal procedures for the L2 (as automatic processes), diacritic features can be stored and unified between the head of a phrase and its modifiers. This enables the learner to produce phrasal morphemes. Once phrasal procedures are present, Appointment Rules and the S-procedure can be developed. This means that the functional destination of phrases can be determined and phrases can be assembled into sentences. The fifth stage concerns subordinate clauses, or more precisely the distinction between main and subordinate clauses (Pienemann, 1998).

Processability Theory is manifested in Teachability and Learnability hypotheses. The Teachability hypothesis argues that acquisition is not aligned with the requirements of teaching, rather, formal instruction is delineated by the confinements of natural acquisition processes. In other words, for instruction to be effective, teachers need to incorporate the naturally occurring processes which take place outside the classroom into their teachings. As a complementary hypothesis, the Learnability hypothesis claims that "instruction can only enhance acquisition by means of teaching a learnable language at a given time" (Gholami \& Zeinolabedini, 2018, p. 3). 


\subsection{The Role of WCF in Processability Theory}

As Pienemann (1998, p. 250) explains, Teachability Hypothesis (as well as Processability Theory in general) predicts that the "stages of acquisition cannot be skipped through formal instruction" and the "instruction will be beneficial if it focuses on structures from the next stage".

That is because the information in each stage needs to be processed before the next stage begins. Corrective Feedback as an instructional tool is no exception for Processability theorists. Di Biase (2008) in a quasi-experimental study investigated the beneficial effects of Focus-on-form (or what he calls Form-oriented) instruction on Italian as L2 learners' acquisition of the L2 forms. He concluded that "focused feedback that is developmentally appropriate is even more beneficial for the learners. Processability turns out to be the key element for both instruction and feedback" (p. 197).

Most existing experimental studies on Processability Theory focus on spontaneous oral language, and written language is underresearched by Processability Theory scholars. This focus on oral data is due to the reliance of Processability Theory on Levelt's (1989) Speech Production Model (which is concerned with memory and online processing speed) and/or the researchers' attempt "to avoid the influence of metalinguistic knowledge" which is more prevalent in writing (Spinner, 2011, p. 537).

Håkansson and Norrby (2007) were probably the first who investigated the role of instruction in L2 writing from a PT perspective. They concluded that the developmental stages cannot be skipped even in written language. This has been reiterated in Håkansson and Norrby (2010). More recently, Dyson (2019) has also found that both "spoken and written results imply that instruction cannot make learners skip stages but may help unready learners progress" (p. 72). Di Biase (personal communication, April 6, 2019) similarly believes that "feedback of any kind must be developmentally moderated" to be effective.

\section{Emergentist Theories}

Emergentism is an umbrella term given to a set of cognitive theories which stress "the interaction between organism and environment and that denies the existence of pre-determined, domainspecific faculties or capacities" (Gregg, 2003, p. 95) or in other words the Chomskyan Universal Grammar. Two prime examples of emergentist theories in SLA are Associative 
Cognitive CREED and Competition Model. Below, these theories are briefly introduced, and the role of WCF in each is discussed.

\subsection{Associative Cognitive CREED Theory}

One theoretical framework that is based on the tenets of emergentism is Associative Cognitive CREED model which holds that SLA is Construction-based, Rational, Exemplar-driven, Emergent, and Dialectic. N. Ellis (2006) believes that language learning just like any other kind of human learning is both associative (in a behavioral form-function mapping sense) and cognitive (a more conscious and explicit learning process). He claims that language learning involves the processes of learning and recycling language constructions. Constructions are "symbolic units that associate morphological, syntactic and lexical form with particular semantic, pragmatic and discourse functions" (Mitchell, Myles, \& Marsden, 2013, p. 103). By proposing that learning is rational, N. Ellis means that learners predict the relevant constructions to be used in a particular context. This is done based on the principles of frequency, recency, and salience of the utterance. In other words, learners can predict when /w $\mathrm{n}$ / refers to 'one' and when it refers to 'won'. To be able to make the aforementioned predictions, learners rely on their ability to make the rules out of exposure to ample examples through inductive reasoning. Similar to the previous tenet, learning emerges as a result of experience with the language as it is used, rather than being innately there. The claim that SLA is dialectic has also been resonated in Interactionist and Sociocultural theories. It means that learning takes place through interaction with others; be it negotiation with peers or teacher's instruction.

\subsection{The Role of WCF in Associative Cognitive CREED Theory}

The role of WCF in this model has been addressed only minimally. N. Ellis and his followers believe that learning is mainly implicit as learning is the result of inductive reasoning not learning the rules explicitly. However, N. Ellis does not claim that language learning is merely an implicit process. Drawing on Schmidt's (2001) Noticing Hypothesis, N. Ellis (2005, p. 305) states that "[t]he primary conscious involvement in SLA is the explicit learning involved in the initial registration of pattern recognizers for constructions that are then tuned and integrated into the system by implicit learning during subsequent input processing”. Elsewhere, N. Ellis (2006, p. 111) more explicitly confirms the efficacy of corrective feedback by explicating that SLA involves 
"the learner in a conscious tension between the conflicting forces of their current interlanguage productions and the evidence of feedback, either linguistic, pragmatic, or metalinguistic, that allows socially scaffolded development".

\subsection{Competition Model}

The Competition Model debuted in the work of Bates and MacWhinney (1982) as a mechanistic explanation of L1 acquisition. The theoretical underpinnings of the Unified Competition Model (UCM) can be found in Saussurean linguistics. The model takes as its starting point the linguistic sign as a set of mappings between forms and functions. Forms are the external phonological, lexical, and syntactic features of language and functions refer to the intended communicative meaning of language usage. In this model, forms are mapped to functions such as agency, topicality, perspective, first mover, causer, volitional agent, and so on (MacWhinney, 1992).

The name of this model is taken from the 'competition' which is formed among various cues signaling a certain function. Cue is "an information source that allows the language user to successfully link linguistic form with meaning” (Li \& MacWhinney, 2013, p. 1). For instance, in the clause 'the book she enjoys a lot' there is a competition between the forms 'She', 'book', and 'a lot' for the role of the agent for the verb 'enjoys'. 'She' is the strongest for being the agent as it is nominative in terms of case and also agrees with the verb 'enjoys'. R. Ellis (2008, p. 475) maintains that there are three factors in determining the useful cue, cue reliability (i.e., "the extent to which a cue always maps the same form onto the same function"), cue availability (i.e., "how often the cue is available in the input"), and conflict validity (i.e., "whether a cue 'wins' or 'loses' when it appears in competitive environment").

\subsection{The Role of WCF in Competition Model}

The most important claim in the UCM is that learning requires attention. If the learner receives comprehensible input and can pay attention to that input, then corrective feedback is not crucial. However, this applies most directly to L1 learning, rather than instructed L2 learning. The role of implicit learning in L2 acquisition has always been a contentious issue. The question is whether implicit learning requires that the learner not attend to the input. The UCM holds that, without a basic level of attention, learning will not take place and if there are input and attention, then learning can definitely occur. However, beyond that, the UCM claims that corrective feedback can 
further facilitate learning when there are comprehensible input and attention. In such cases, experiments show that providing basic corrective feedback definitely helps learning (McDonald, 1986). The next question is whether feedback should involve rules. Experiments with the UCM show that initially, corrective feedback without rules is almost as good as corrective feedback with rules. However, for retention, positive and negative feedback along with simple rules is superior; thus, complex rule feedback has to be avoided and the rules must reduce to simple cues.

Although this model does not explicitly address the issue of corrective feedback in writing, based on the aforementioned discussion, it can be concluded that while providing WCF, complex rule feedback must be avoided.

\section{Interactionist Theories}

\subsection{Interaction Hypothesis}

The theoretical underpinnings of Long's $(1983,1985)$ first version of his Interaction Hypothesis have a lot in common with the underlying assumptions of Krashen's Monitor Model regarding the distinction between acquisition and learning. However, he shifted the attention from comprehensible input to the role of interaction in L2 acquisition. Long posits that for acquirers to receive more comprehensible input, they need to be engaged in interaction and negotiation with their peers and teachers. This negotiation, he believes, must be a negotiation for meaning (rather than form) which includes clarification request, repetition, confirmation check, etc. In other words, Long claims that for more effective learning the focus must be on the interactionally modified input rather than comprehensible input.

In his revised version of the Interaction Hypothesis, Long (1996) breaks from Krashen's UG-based views and gives more credit to the environmental factors. In this reformulated version, Long highlights the processes by which input is converted into intake through selective attention and focus on form.

\subsection{Comprehensible Output Hypothesis}

Similar to Long's hypothesis, Swain (1985) claimed that comprehensible input is not sufficient for successful second language acquisition, but that opportunities for Non-Native Speakers (NNSs) to produce language in meaningful ways are also necessary. She suggested that when learners are 
engaged in the negotiation of meaning and talking about the language they are, in those moments, engaged in learning the language.

Swain (1985) argued that the role of learner production is independent in many ways of the role of comprehensible input. She proposed a hypothesis relating to the second language (L2) learner's production comparable to that of comprehensible input put forward by Krashen. This she termed the Comprehensible Output Hypothesis for SLA. According to her, there is no better way to test the extent of one's knowledge (linguistic or otherwise) than to have to use that knowledge in some productive way- whether it is explaining a concept to someone (i.e., teaching) or writing a computer program, or in the case of language learning, getting even a simple idea across, and in doing so, he might modify a previous utterance or he might try out a form that he had not used before.

The basic tenet of the comprehensible output hypothesis is that producing the L2 forms in meaningful ways 'pushes' learners to make their output more precise, coherent, and appropriate. Also, it can "force the learner to pay attention to the means of expression needed in order to successfully convey his or her own intended meaning" (Swain, 1985, p. 249), Thus, output production presents learners with a unique opportunity to process language that may not be necessary for simple comprehension. Swain acknowledged the role of comprehensible input in SLA but argued that Comprehensible Output is also a necessary mechanism which aids SLA in many ways. She contends that "its role is, at minimum, to provide opportunities for contextualized, meaningful use, to test out hypothesis about the target language, and to move the learner from a purely semantic analysis of the language to a syntactic analysis of it” (Swain, 1985, p. 252).

\subsection{The Role of WCF in Interactionist Theories}

Long's revised Interaction Hypothesis emphasizes the contributions of negative evidence (corrective feedback):

Negative feedback obtained during negotiation work or elsewhere may be facilitative of L2 development, at least for vocabulary, morphology, and language-specific syntax, and essential for learning certain specifiable L1-L2 contrasts. (1996, p. 414)

This perspective is instantiated in Form-Focused Instruction where proactive and reactive focus on form (corrective feedback) are recognized as essential components of a second language classroom. 
Although both Interaction and Comprehensible Output Hypotheses are originally relevant to oral language, with the expansion of Form-Focused Instruction there are studies which assert the applicability of these hypotheses to L2 writing (Swain, 1998; Qi \& Lapkin, 2001; Sachs \& Polio, 2007). Sachs and Polio (2007), for instance, investigated the efficacy of three WCF provision methods namely, error correction, reformulation, and reformulation + think-aloud. The results were indicative of the fact that the participants' awareness in the reformulation + thinkaloud condition suggested that noticing of feedback was related to the accuracy of subsequent revisions. Similarly, Qi and Lapkin (2001) studied the relationship of noticing, both in the composing stage (Stage 1) and the reformulation stage (Stage 2, where learners compare their own text to a reformulated version of it), to the improvement of the written product in the posttest (Stage 3) of a three-stage writing task. The findings suggest that while composing and reformulation promote noticing, the quality of noticing, which relates directly to L2 writing improvement, is different for learners with different levels of L2 proficiency.

\section{Sociocultural Theories}

As a reaction to generative and cognitive views toward learning, Vygotsky (1978) claimed that knowledge is socially co-constructed. Central to his theory is the concept of Zone of Proximal Development (ZPD) which refers to an area of learning between what learners can do alone and what they can do with assistance and guidance from a more competent other (peers or teachers). This assistance is usually in the form of collaborative scaffolding (Wood, Bruner, \& Ross, 1976). Donato (1994, p. 40) defines scaffolding as "a situation where a knowledgeable participant can create supportive conditions in which the novice can participate, and extend his or her current skills and knowledge to higher levels of competence".

Another essential component of Sociocultural Theory is the concept of mediation. Mediation is "the process through which humans deploy culturally constructed artifacts, concepts, and activities to regulate the material world or their own and each other's social and mental activity" (Lantolf \& Thorne, 2006, p. 79). Lantolf classifies L2 mediation into three types: Mediation by others in social interaction, mediation by the self through private speech, and mediation by artifacts rather than language. Lantolf elaborates on the social mediation in terms of expert/novice mediation and also peer-mediation which is applicable to SLA classroom. 


\subsection{Activity Theory}

Activity Theory, originally proposed by Leontiev (1978), is a conceptual framework in SLA originating from Sociocultural Theory. Activity Theory is a framework or descriptive tool (Nardi, 2005) that provides "a unified account of Vygotsky's proposals on the nature and development of human behavior" (Lantolf, 2006, p. 8). Contradictions constitute a key concept or principle in Activity Theory. They are not simply conflicts or problems but are "historically accumulating structural tensions within and between activity systems" (Engeström, 2001, p. 137). They generate "disturbances and conflicts, but also innovative attempts to change the activity" (Engeström, 2001, p. 134).

A model of the structure of activity system was developed by Engeström (1987) which incorporates the interacting elements of subject, object, tools (instruments or artifacts), division of labor, community, rules, and outcome, as depicted in Figure 2.

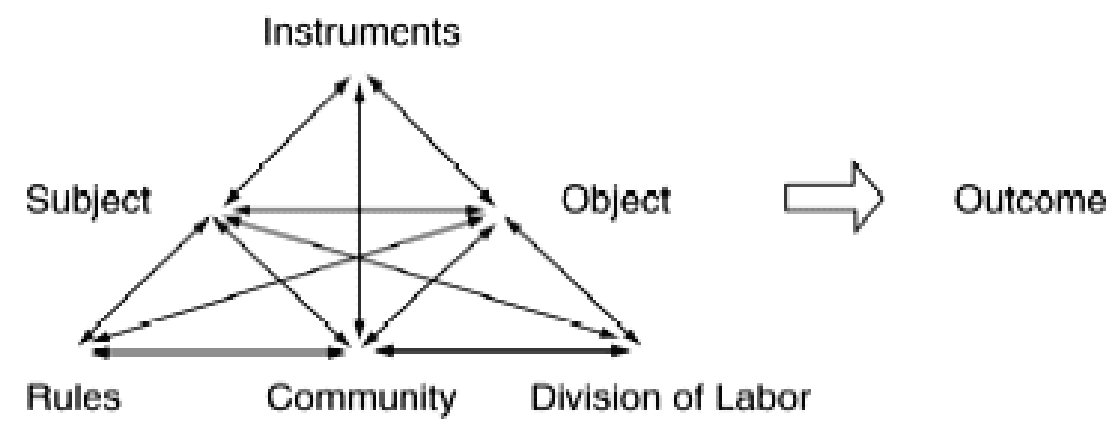

Figure 2: Components of the activity system (Engeström, 1987)

To Engeström (2001), the top sub-triangle may be seen as the "tip of the iceberg" (p. 134) representing individual and group actions embedded in a collective activity system. It, therefore, indicates that the subject is mediated by artifacts to reach the object (Prenkert, 2010).

The three components of the activity system at the bottom of the diagram including, rules, community, and division of labor are attached to the upper triangle to expand the core meaning of mediation in this theory. Rules are defined as "the explicit and implicit regulations, norms and conventions that constrain actions and interactions within the activity system"; community is "multiple individuals and/or subgroups who share the same general object"; and finally division of labor refers to "both the horizontal division of tasks between the members of the community and to the vertical division of power and status" (Engeström, 1993, p. 67). 


\subsection{The Role of WCF in Sociocultural Theories}

One of the earliest works investigating the role of WCF within the framework of Sociocultural Theory is Aljaafreh and Lantolf's (1994) study where they proposed a regulatory scale which was comprised of a list of corrective feedback strategies beginning with implicit correction moves and gradually moving toward more explicit feedback provided orally in response to the learners' written errors. The same approach has been adopted by Nassaji and Swain (2000) and Nassaji (2011) in all of which negotiated/scaffolded WCF has been proved effective.

More recently, Zhu and Mitchell (2012), Lee (2014), Mak and Lee (2014), Yu and Lee (2015), Lee (2017), and Abbaspour, Atai, and Maftoon (2020) have investigated the role of WCF through the lens of Activity theory. These studies also concluded that socioculturally-mediated WCF can substantially improve the quality of the learners' writings. Lee (2014) believes that to be more effective, conventional feedback provision methods need to be substituted with practices which cater for process-oriented approaches to teaching writing; therefore, WCF can play a mediating role in student learning.

\section{Conclusion}

This article reflects on various SLA theories with respect to the importance they place on Written Corrective Feedback. For this purpose, seven major categories of SLA theories namely, UG-based theories, Modular theories, Emergentist theories, Information Processing theories, Input Processing theories, Interactionist theories, and Sociocultural Theory were briefly reviewed and their positions regarding the role of WCF in L2 acquisition were investigated. Accordingly, the results obtained from the available empirical studies carried out within each theoretical framework with respect to WCF were analyzed.

The majority of the theories attached great significance to the role of WCF; however, some expressed reservations or even vigorously denounced it. Overall, UG-based and Modular theories posit that WCF does not play any crucial roles in L2 acquisition and is redundant. Input processing theories acknowledge that WCF has only a limited impact on learning. The proponents of these theories either believe that explicit WCF is ineffective or feedback must be developmentally moderated as the learners cannot skip the natural stages of acquisition even when they receive corrective feedback. On the other end of the continuum are the theories which consider WCF an effective technique in SLA. Information processing theories claim that WCF in the form of 
reformulation can convert declarative knowledge to procedural knowledge. Hartshorn et al (2010) also believe that meaningful, timely, constant, and manageable WCF will lead to learning. Emergentist theories, which have been the basis of Noticing Hypothesis, support the view that explicit learning is primary in SLA; therefore, WCF is crucial in learning. Interactionists also consider WCF as an integral part of language. This view has been reflected in Form-focused Instruction where feedback plays a central role. Similarly, Sociocultural theories are supportive of using WCF in writing classes. However, the provided feedback in order to lead to uptake must be scaffolded and in the learners' Zone of Proximal Development. Negotiation of forms and meanings are common techniques in classes based on SCT.

These fundamental contradictions are rooted in the fact that these theories adhere to different and at times opposing philosophical, psychological, or linguistic camps. In sum, whether the theories consider WCF effective or ineffective boils down to one fundamental question - does explicit instruction lead to learning? It is hoped that this review article can shed light on some ambiguities regarding the role of WCF in learning from the perspective of various theories in the SLA sphere.

\section{Acknowledgment}

The author wishes to sincerely thank Alessandro Benati, Sussane Carroll, Bruno Di Biase, Bronwen Dyson, Nick Ellis, Brian MacWhinney, Michel Paradis, Bill VanPatten, and Yanyin Zhang who kindly went out of their way to generously provide us with invaluable insight regarding the theories in which they are leading figures.

\section{References}

Abbaspour, E., Atai, M., Maftoon, P. (2020). The effect of scaffolded written corrective feedback on Iranian EFL learners' writing quality: An activity theory perspective. International Journal of Foreign Language Teaching and Research, 8(30), 177-196.

Aljaafreh, A., \& Lantolf, J. P. (1994). Negative feedback as regulation and second language learning in the zone of proximal development. The Modern Language Journal, 78, 465-83. Anderson, J. R. (1982). Acquisition of cognitive skill. Psychological Review, 89, 369-403.

Anderson, J. R. (1983). The architecture of cognition. Cambridge, MA: Harvard University Press. 
Anderson, J. R., \& Gluck, K. (2001). What role do cognitive architectures play in intelligent tutoring systems? In D. Klahr \& S. M. Carver (Eds.), Cognition and instruction: Twentyfive years of progress (pp. 227-262). Hillsdale, NJ: Lawrence Erlbaum.

Anderson, J. R., \& Reder, L. M. (1999). The fan effect: New results and new theories. Journal of Experimental Psychology: General, 128, 186-197.

Anderson, J. R., Fincham, J. M., \& Douglass, S. (1999). Practice and retention: A unifying analysis. Journal of Experimental Psychology: Learning, Memory, and Cognition, 25(5), 1120-1136.

Bates, E., \& MacWhinney, B. (1982). Functionalist approaches to grammar. In E. Wanner \& L. Gleitman (Eds.), Language acquisition: The state of the art (pp. 173-218). New York, NY: Cambridge University Press.

Benati, A. (2004). The effects of structured input activities and explicit information on the acquisition of the Italian future tense. In B. VanPatten (Ed.), Processing instruction: Theory, research, and commentary (pp. 207-225). Mahwah, NJ: Erlbaum.

Bitchener, J., \& Ferris, D. R. (2012). Written corrective feedback in second language acquisition and writing. New York, NY: Routledge.

Byrne, M. D. (2002). Cognitive architecture. In A. Sears \& J. A. Jacko (Eds.), The humancomputer interaction handbook: Fundamentals, evolving technologies and emerging applications (pp. 97-117). Boca Raton, FL: CRC Press.

Carroll, S. E. (1999). Putting 'input' in its proper place. Second Language Research, 15(4), 337388.

Carroll, S. E. (2001). Input and evidence: The raw material of second language acquisition. Amsterdam, The Netherlands: John Benjamins.

Carroll, S. E. (2002). Induction in a modular learner. Second Language Research, 18(3), 224-249.

Chandler, J. (2003). The efficacy of various kinds of error feedback for improvement in the accuracy and fluency of L2 student writing. Journal of Second Language Writing, 12, 267296.

Di Biase, B. (2008). Focus-on-form and development in L2 learning. In J. U. Keßler (Ed.), Processability approaches to second language development and second language learning (pp. 197-219). Newcastle upon Tyne, UK: Cambridge Scholars Publishing. 
Donato, R. (1994). Collective scaffolding in second language learning. In J. P. Lantolf \& G. Appel (Eds.), Vygotskian approaches to second language research (pp. 33-56). Westport, CT: Ablex Publishing.

Dulay, H. C., \& Burt, M. K. (1974). Natural sequences in child second language acquisition. Language Learning, 24(1), 37-53.

Dyson, B. P. (2019). Are speech and writing teachable? Re-examining developmental constraints on pedagogy. In R. Arntzen, G. Håkansson, A. Hjelde, \& J. Keßler (Eds.), Teachability and learnability across languages (pp. 72-93). Amsterdam, The Netherlands: John Benjamins.

Ellis, N. C. (2006). Cognitive perspectives on SLA: The associative-cognitive CREED. AILA Review, 19(1), 100-121.

Ellis, R. (2008). The study of second language acquisition (2 ${ }^{\text {nd }}$ Ed.). Oxford, UK: Oxford University Press.

Engeström, Y. (1987). Learning by expanding: An activity-theoretical approach to developmental research. Helsinki, Finland: Orienta-Konsultit.

Engeström, Y. (1993). Developmental studies of work as a test bench of activity theory: the case of primary care medical practice. In J. Lave, \& S. Chaiklin (Eds.), Understanding practice: Perspectives on activity and context (pp. 64-103). Cambridge, UK: Cambridge University Press.

Engeström, Y. (2001). Expansive learning at work: Toward an activity-theoretical reconceptualization. Journal of Education and Work, 14, 133-156.

Evans, N., Hartshorn, K. J., \& Strong-Krause, D. (2011). The efficacy of dynamic written corrective feedback for university-matriculated ESL learners. System, 39, 229-239.

Ferris, D. (1999). The case for grammar correction in L2 writing classes: A response to Truscott (1996). Journal of Second Language Writing, 8, 1-11.

Fodor, J. A. (1983). The modularity of mind: An essay on faculty psychology. Cambridge, MA: The MIT Press.

Gholami, J., \& Zeinolabedini, M. (2018). Learnability and teachability hypothesis. In J. I. Liontas (Ed.), The TESOL encyclopedia of English language teaching. New York, NY: John Wiley \& Sons, Inc. 
Håkansson, G., \& Norrby, C. (2007). Processability Theory applied to written and oral L2 Swedish. In F. Mansouri (Ed.), Second language acquisition research: Theoryconstruction and testing (pp. 81-94). Cambridge, UK: Cambridge Scholars Press.

Håkansson, G., \& Norrby, C. (2010). Environmental influence on language acquisition: Comparing second and foreign language acquisition of Swedish. Language Learning, $60(3), 628-650$.

Hartshorn, K., Evans, N., Merrill, P., Sudweeks, R., Strong-Krause, D., \& Anderson, N. (2010). Effects of dynamic corrective feedback on ESL writing accuracy. TESOL Quarterly, 44, 84-109.

Henry, N., Culman, H., \& VanPatten, B. (2009). More on the effects of explicit information in instructed SLA: A partial replication and a response to Fernández (2008). Studies in Second Language Acquisition, 31(4), 559-575.

Jackendoff, R. (1997). The architecture of the language faculty. Cambridge: The MIT Press.

Jackendoff, R. (2002). Foundations of language: Brain, meaning, grammar, evolution. Oxford, UK: Oxford University Press.

Johnson, K. (1988). Mistake correction. ELT Journal, 42(2), 89-96.

Johnson, K. (1996). Language teaching and skill learning. Oxford, UK: Blackwell.

Karmiloff-Smith, A. (1986). Stage/structure versus phase/process in modelling linguistic and cognitive development. In I. Levin (Ed.), Stage and structure (pp. 164-190). Hillsdale, NJ: Erlbaum.

Krashen, S. D. (1977). Some issues relating to the Monitor Model. In H. D. Brown, C. Yorio \& R. Crymes (Eds.), On TESOL'77: Teaching and learning English as a second language: Trends in research and practice (pp. 144-158). Washington, DC: TESOL.

Krashen, S. D. (1981). Second language acquisition and second language learning. Oxford, UK: Pergamon.

Krashen, S. D. (1982). Principles and practice in second language acquisition. Oxford, UK: Pergamon.

Krashen, S. D. (1984). Writing: Research, theory, and applications. Oxford, UK: Pergamon.

Krashen, S. D. (2003). Explorations in language acquisition and use: The Taipei lectures. Portsmouth, UK: Heinemann. 
Kuutti, K. (1996). Activity theory as a potential framework for human-computer interaction research. In B. A. Nardi (Ed.), Context and consciousness: Activity theory and humancomputer interaction (pp. 17-44). Cambridge, MA: The MIT Press.

Lantolf, J. P. (2006). Sociocultural theory and L2: State of the art. Studies in Second Language Acquisition, 28, 67-109.

Lantolf, J. P., \& Thorne, S. L. (2006). Sociocultural theory and the genesis of second language development. Oxford, UK: Oxford University Press.

Lee, I. (2014). Revisiting teacher feedback in EFL writing from sociocultural perspectives. TESOL Quarterly, 48(1), 201-213.

Lee, I. (2017). Classroom writing assessment and feedback in L2 school contexts. Singapore, Singapore: Springer.

Leontiev, A. N. (1978). Activity, consciousness, and personality. Englewood Cliffs, NJ: PrenticeHall.

Levelt, W.J.M. (1989). Speaking: From intention to articulation. Cambridge: The MIT Press.

Li, P., \& MacWhinney, B. (2013). Competition model. In C. A. Chapelle (Ed.), The encyclopedia of applied linguistics. Malden, MA: Wiley.

Long, M. H. (1983). Linguistic and conversational adjustments to non-native speakers. Studies in Second Language Acquisition, 5, 177-193.

Long, M. H. (1996). The role of the linguistic environment in second language acquisition. In W. C. Ritchie, \& T. K. Bhatia (Eds.), Handbook of second language acquisition (pp. 413468). New York, UK: Academic Press.

MacWhinney, B. (1992). Transfer and competition in second language learning. In R. Harris (Ed.), Cognitive processing in bilinguals (pp. 371-390). Amsterdam, The Netherlands: Elsevier.

Mak, P., \& Lee, I. (2014). Implementing assessment for learning in L2 writing: An activity theory perspective. System, 47, 73-87.

McDonald, J. L. (1986). The development of sentence comprehension strategies in English and Dutch. Journal of Experimental Child Psychology, 41, 317-35.

McLaughlin, B. (1987). Theories of second language acquisition. London: Edward Arnold.

Meisel, J., Clahsen H., \& Pienemann, M. (1981). On determining developmental stages in natural second language acquisition. Studies in Second Language Acquisition, 3(1), 109-35.

Nardi, B. (2005). Objects of desire: Power and passion in collaborative activity. Mind, Culture, 
and Activity, 12, 37-51.

Nassaji, H. (2011). Correcting students' written grammatical errors: The effects of negotiated versus nonnegotiated feedback. Studies in Second Language Learning and Teaching, 1(3), $315-334$.

Nassaji, H., \& Swain, M. (2000). Vygotskian perspective on corrective feedback in L2: The effect of random versus negotiated help on the learning of English articles. Language Awareness, 9, 34-51.

Paradis, M. (2009). Declarative and procedural determinants of second languages. Amsterdam, The Netherlands: John Benjamins Publishing.

Pienemann, M. (1984). Psychological constraints on the teachability of languages. Studies in Second Language Acquisition, 6(2), 186-214.

Pienemann, M. (1989). Is language teachable? Psycholinguistic experiments and hypotheses. Applied Linguistics, 10(1), 52-79.

Pienemann, M. (1998). Language processing and second language development: Processability theory. Amsterdam, The Netherlands: John Benjamin.

Pienemann, M. (2005). Discussing processability theory. In M. Pienemann (Ed.), Crosslinguistic aspects of processability theory (pp. 61-83). Amsterdam, The Netherlands: John Benjamins.

Polio, C. (2012). The relevance of second language acquisition theory to the written error correction debate. Journal of Second Language Writing, 21(4), 375-389.

Prenkert, F. (2010). Tracing the roots of activity systems theory: An analysis of the concept of mediation. Theory \& Psychology, 20(5), 641-665.

Qi, D. S., \& Lapkin, S. (2001). Exploring the role of noticing in a three-stage second language writing task. Journal of Second Language Writing, 10, 277-303.

Sachs, R., \& Polio, C. (2007). Learners' uses of two types of written feedback on an L2 writing revision task. Studies in Second Language Acquisition, 29, 67-100.

Sanz, C., \& Morgan-Short, K. (2004). Positive evidence vs. explicit rule presentation and explicit negative feedback: A computer assisted study. Language Learning, 54, 35-78.

Schmidt, R. (2001). Attention. In P. Robinson (Ed.), Cognition and second language instruction (pp. 3-32). Cambridge, UK: Cambridge University Press. 
Sharwood Smith, M. (2013). Only connect: The interface debate in second language acquisition. In K. Droz'dział-Szelest \& M. Pawlak (Eds.), Psycholinguistic and sociolinguistic perspectives on second language learning and teaching. Berlin, Germany: SpringerVerlag.

Spinner, P. (2011). Second language assessment and morphosyntactic development. Studies in Second Language Acquisition, 33(4), 529-561.

Sun, Y. A. (2008). Input processing in second language acquisition: A discussion of four input processing models. Working Papers in TESOL \& Applied Linguistics, 8(1), 1-10.

Swain, M. (1985). Communicative competence: Some roles of comprehensible input and comprehensible output in its development. In S. Gass \& C. Madden (Eds.), Input and second language acquisition (pp. 235-256). Rowley, MA: Newbury House.

Swain, M. (1998). Focus on form through conscious reflection. In C. Doughty \& J. Williams (Eds.), Focus on form in classroom second language acquisition (pp. 64-81). Cambridge, UK: Cambridge University Press.

Swain, M., \& Lapkin, S. (1995). Problems in output and the cognitive processes they generate: A step towards second language learning. Applied Linguistics, 16, 371-391.

Truscott, J. (1996). The case against grammar correction in L2 writing classes. Language Learning, 46, 327-369.

VanPatten, B. (2002). Processing instruction: An update. Language Learning, 52, 755-803.

VanPatten, B. (2009). Processing matters in input enhancement. In T. Piske \& M. Young-Scholten (Eds.), Input matters (pp. 47-61). Clevedon, UK: Multilingual Matters.

VanPatten, B. (Ed.). (2004). Processing instruction. Mahwah, NJ: Lawrence Erlbaum Associates.

VanPatten, B., \& Cardieno, T. (1993). Explicit instruction and input processing. Studies in Second Language Acquisition, 15, 225-243.

VanPatten, B., \& Oikkenon, S. (1996). Explanation versus structured input in processing instruction. Studies in Second Language Acquisition, 18, 495 - 510.

Whong, M. (2007). Seeking consensus: Generative linguistics and language teaching. Leeds Working Papers in Linguistics and Phonetics, 12, 143-155.

Wong, W. 2004. The nature of processing instruction. In B.VanPatten (Ed.), Processing instruction (pp. 33-63). Mahwah, NJ: Lawrence Erlbaum Associates. 
Wood, D., Bruner, J. S., \& Ross, G. (1976). The role of tutoring in problem-solving. Journal of Child Psychology and Child Psychiatry, 17(2), 89-100.

Yu, S., \& Lee, I. (2015). Understanding EFL students' participation in group peer feedback of L2 writing: A case study from an activity theory perspective. Language Teaching Research, 19(5), 572-593

Zhu, W., \& Mitchell, D. (2012). Participation in peer response as activity: An examination of peer response stances from an activity theory perspective. TESOL Quarterly, 46, 362-386.

\begin{abstract}
About the Author
Ehsan Abbaspour holds a Ph.D. in Teaching English as a Foreign Language from Science and Research Branch, Islamic Azad University, Tehran, Iran. His research interests include Second Language Acquisition and Written Corrective Feedback.
\end{abstract}

